Research article

\title{
Graphene materials from microwave-derived carbon precursors
}

\author{
Zoraida González ${ }^{\mathrm{a}, *}$, Beatriz Acevedo ${ }^{\mathrm{b}}$, Georgeta Predeanu ${ }^{\mathrm{c}}$, Sorin M. Axinte ${ }^{\mathrm{d}}$, \\ Marius-Florin Drăgoescu ${ }^{\mathrm{d}}$, Valerica Slăvescu ${ }^{\mathrm{c}}$, Juan J. Fernandez ${ }^{\mathrm{e}}$, Marcos Granda ${ }^{\mathrm{a}}$, \\ Grazyna Gryglewicz ${ }^{\mathrm{f}}$, Sonia Melendi-Espina ${ }^{\mathrm{b}, "}$ \\ ${ }^{a}$ Instituto de Ciencia y Tecnología del Carbono (INCAR-CSIC), Francisco Pintado Fe 26, 33011 Oviedo, Spain \\ ${ }^{\mathrm{b}}$ School of Engineering, University of East Anglia, Norwich Research Park, NR4 7TJ, Norwich, UK \\ ${ }^{\mathrm{c}}$ Faculty of Applied Chemistry and Materials Science, Research Center for Environmental Protection and Eco-friendly Technologies, University Politechnica of Bucharest, \\ 1 Polizu St., 011061 Bucharest, Romania \\ ${ }^{\mathrm{d}}$ Claudiu TopRom SRL, Bucharest, Romania \\ e Industrial Química del Nalón, S.A., 33100, Trubia, Spain \\ ${ }^{\mathrm{f}}$ Department of Process Engineering and Technology of Polymer and Carbon Materials, Wrocław University of Science and Technology, Gdańska 7/9, 50-344 Wrocław, \\ Poland
}

\section{A R T I C L E I N F O}

\section{Keywords:}

Microwave heating

Conventional heating

Carbon precursors

Energy saving

Graphene materials

\begin{abstract}
A B S T R A C T
Anthracene oil has been used as raw material for the production of carbon precursors via conventional and microwave technologies. Cokes with comparable characteristics have been obtained, suggesting that their structural order is primarily reliant on the precursor rather the heating method. However, microwave route is a more energy efficient process, achieving electricity savings of up to $60 \%$. Furthermore, graphites produced from microwave-derived precursors show an excellent graphitization degree, which makes them appropriate starting resources for the synthesis of graphene-like materials with similar characteristics to those obtained from conventional means. Therefore, microwave-assisted heating approach appears to be a suitable and energy saving alternative for the production of carbon precursors.
\end{abstract}

\section{Introduction}

Graphene is a 2D one-atom-thick planar sheet of $\mathrm{sp}^{2}$ bonded carbon atoms, densely packed in a honeycomb crystalline lattice. The properties arising from their structure make graphene and graphene-like materials excellent candidates for a variety of applications, ranging from flexible nanoelectronics and sensors to polymer nanocomposites and separation membranes [1]. Consequently, since the isolation of graphene by micromechanical exfoliation [2], physical and chemical methods have so far been developed to produce graphene materials for research and commercial purposes. Current synthesis methods comprise both bottomup and top-down approaches [3]. In bottom-up procedures, selfassembly of carbon atoms to form graphene sheets is entailed, while in top-down routes, graphite is used as the precursor to produce graphene materials [3]. Top-down technologies can be easily scaled up at a reasonable cost [4], therefore they are considered more promising from an industrial point of view. It should be noted however that natural graphite is a limited resource found only in a few countries, such as
China, India or Brazil [5]. Fortunately, synthetic graphite can be obtained from a wide variety of carbon precursors [6].

In this context, anthracene oil (AO), a fraction obtained from coal tar by distillation consisting on a mixture of polyaromatic (from 2 to 4 aromatic rings) hydrocarbons [7], has been widely used as carbon precursor $[7,8]$. Even though it is considered a low-cost residue from the carbochemical industry, it is an excellent raw material for the production of synthetic pitches $[7,8]$, which at the same time are suitable precursors for the synthesis of high added-value products, such as graphite and graphene materials [9]. The first step in the production of graphite from AO-pitches involves their polymerization at high temperatures in absence of air [10]. During this process, pitches undergo a series of physical and chemical transformations at higher temperatures, resulting in the formation of an infusible hydrocarbon polymer (coke) [10]. These polymerization reactions usually take place by the input of energy provided by thermal heating in conventional electric furnaces. Nevertheless, this energy could be provided in other ways. In this regard, it has been recently reported the successful synthesis of AO-pitches by

\footnotetext{
* Corresponding authors.

E-mail addresses: zoraidag@incar.csic.es (Z. González), s.melendi-espina@uea.ac.uk (S. Melendi-Espina).
} 
microwave heating saving up to $20 \%$ of the required electric energy [11], which represents an excellent improvement for the production of carbon precursors.

Most carbon materials are excellent microwave absorbers, so they can be easily produced or transformed by microwave heating. Microwave technology offers a number of advantages, such as non-contact and rapid heating, quick start and stopping, high level of safety and automation etc., in comparison to conventional heating [12]. Consequently, the combination of carbon materials and microwave technology has attracted much interest in recent years. Microwave heating has shown its suitability for the synthesis and functionalisation of nanotubes and nanofibers [13-15], as well as its potential to significantly reduce the time and number of steps required for a successful functionalisation compared to conventional approaches, which pave the way for a more cost-effective process [16]. In addition, the production of graphitic materials has been also gained industrial interest. In this regard, a microwave reactor for the production of expanded graphite has been patented [17] and Mitsubishi Heavy Industries Ltd. claimed the successful production of graphite materials via microwave heating [12].

Therefore, in this work we have investigated the prospects of microwave treatment in the fabrication of graphitizable cokes to be used as suitable precursors for the synthesis of graphene materials with physicochemical properties comparable to those from conventional heating routes. Accordingly, two cokes were made following different methods. One of them was synthesized conventionally but from a microwave derived AO-pitch, while the second one was fabricated entirely by microwave heating from AO. A third coke was produced from $\mathrm{AO}$ in a traditional manner for comparison purposes. Graphites were subsequently produced from their corresponding cokes and successively used as starting materials for the synthesis of different batches of graphene materials following the chemical route [18]. Comprehensive characterization of all the synthesized materials was carried out to explore the potential of microwave heating as a successful approach for a more energy efficient synthesis of graphene-like precursors.

\section{Experimental}

\subsection{Synthesis of cokes}

\subsubsection{Synthesis of conventional cokes}

The synthesis of the AO pitch under conventional heating was explained in detail elsewhere [19]. Briefly, airflow was injected at the bottom of a stainless steel reactor and reacted with the AO. After the oxidative treatment, the product was conducted to a second tank in which pressure dropped drastically to vacuum conditions. In this stage, a high distillation of the product took place, assisted by a $\mathrm{N}_{2}$ flow that removed the volatiles, promoting the condensation of aromatic structures as well as eliminating oxygen and other volatiles present in the mixture. The obtained synthetic pitch was introduced in an electric furnace to synthesize the coke. The coking process consisted in two different stages. In the first step, the precursor was heated up to $650{ }^{\circ} \mathrm{C}$ at a heating rate of $2{ }^{\circ} \mathrm{C} / \mathrm{min}$ under $\mathrm{N}_{2}$ atmosphere. 1 bar overpressure was necessary to avoid the distillation of sample maintaining most of the volatile fractions in the matrix, which made the medium more fluid allowing the formation of a more crystalline coke structure and improving the final coke yield [20]. Subsequently, the temperature was raised up to $900{ }^{\circ} \mathrm{C}$ at the same heating rate and also in $\mathrm{N}_{2}$ atmosphere. Overpressure was not necessary, as the volatile content was very low. In this stage, the structural ordering of aromatic layers took place resulting in a more regular graphitic structure. The resulting coke was labelled as CK1.

\subsubsection{Synthesis of cokes from microwave-derived pitches}

Oxidative polymerization of AO was carried out in a microwave apparatus equipped with a multimode applicator and a quartz reactor with a total capacity of 21 . A frequency of $2.45 \mathrm{GHz}$ was established and the AO oxidation stage was conducted based on the air/AO mass ratio of $18.7 \%$. Further details about the equipment and procedure can be found elsewhere [11]. AO was heated up to $360^{\circ} \mathrm{C}$ at a heating rate of $2.5^{\circ} \mathrm{C} /$ min. Once the desired temperature was achieved, the sample was maintained at this temperature for $2.5 \mathrm{~h}$. Subsequently, using the obtained microwave-derived pitch as precursor, the conventional procedure explained in 2.1.1 was followed to produce the corresponding coke, which was labelled as CK2.

\subsubsection{Synthesis of microwave-derived cokes}

The microwaved pitch obtained in 2.1.2 was also used as starting material for the production of the microwave-derived coke. The same microwave equipment detailed in 2.1.2 was employed and the final coking temperature was set at $900{ }^{\circ} \mathrm{C}$ in nitrogen flow with $10 \mathrm{~min}$ of soaking time. Once the reaction finished the system was allowed to cool down and the resulting coke was labelled as CK3.

\subsubsection{Influence of coke synthesis procedure on energy consumption}

Considering the significant energy consumption in high temperature industrial processes, the assessment of the electric energy required for the synthesis of the cokes following conventional electrical heating (CK1) and microwave-assisted technology (CK3) was performed. The electricity consumption was monitored using a digital meter to compare the efficiency and usage of both approaches, taking into account the electrical power and electric energy consumption of the two temperature domains: $<900{ }^{\circ} \mathrm{C}$ (heating time) and $900{ }^{\circ} \mathrm{C}$ (soaking time).

\subsection{Synthesis of graphites}

The three synthesized cokes were ground in a ball mill (Retsch S100, $450 \mathrm{rpm}, 1 \mathrm{~h}$ ) and sieved to a particle size below $75 \mu \mathrm{m}$ prior graphitization. For the synthesis of the respective graphites, cokes were introduced in a Pyrox VI 150/25 furnace where temperature was increased up to $2800{ }^{\circ} \mathrm{C}$ under argon atmosphere. Cokes were subjected to four sequential heating steps. In the first stage, from room temperature up to $700{ }^{\circ} \mathrm{C}$ at a heating rate of $50{ }^{\circ} \mathrm{C} / \mathrm{min}$. From 700 to $1000{ }^{\circ} \mathrm{C}$ the heating process took place at $100{ }^{\circ} \mathrm{C} / \mathrm{min}$. In the third step, temperature was increased up to $2000{ }^{\circ} \mathrm{C}$ at $25{ }^{\circ} \mathrm{C} / \mathrm{min}$. Finally, from 2000 to $2800{ }^{\circ} \mathrm{C}$ temperature was raised much slowly, at $10{ }^{\circ} \mathrm{C} / \mathrm{min}$. The synthesized graphites were labelled as GR1, GR2 and GR3 in consonance with their parent cokes.

\subsection{Synthesis of graphene materials}

A variety of graphene materials were prepared by a modified Hummers method [18] starting from the different synthesized graphites. In a first step, the graphites were oxidized with $\mathrm{NaNO}_{3}$ and $\mathrm{KMnO}_{4}$, in a ratio of 2:1:6 by weight, in presence of $\mathrm{H}_{2} \mathrm{SO}_{4}$ acting as a solvent. After $1 \mathrm{~h}$ at $40{ }^{\circ} \mathrm{C}$ and vigorous stirring, a solution of $\mathrm{H}_{2} \mathrm{O}_{2}$ ( $3 \mathrm{wt} \%$ in distilled water) was added to stop the reaction and to neutralize the excess of $\mathrm{KMnO}_{4}$ used. Then the residual permanganate salts were eliminated by repetitive sedimentation steps via centrifugation ( 5 times with deionized water and 2 times with MilliQ water). After removing the solvent in a rotary evaporator, a solid graphite oxide (GRO) was obtained.

In a subsequent stage, the as obtained GROs were subjected to a thermal exfoliation/reduction process to be transformed into thermally reduced graphene oxides. For this purpose, a stainless steel homemade reactor was employed at a temperature of $300^{\circ} \mathrm{C}$. This temperature was selected as it is required for the blasting, due to the release of water and labile oxygen functional groups [21]. To further recover the carbon lattice and consequently reduce the oxygen functionalities still present on the partially reduced graphene oxides, the samples were treated at $1000^{\circ} \mathrm{C}$, in a tubular furnace with a heating rate of $5^{\circ} \mathrm{C} / \mathrm{min}$ and under nitrogen flow. The obtained thermally reduced graphene oxides (TRGOs) were labelled as TRGOX, with $\mathrm{X}=1,2$ or 3 depending on the graphite used as precursor. 
Table 1

Elemental analysis of the obtained cokes.

\begin{tabular}{|c|c|c|c|c|c|}
\hline & \multicolumn{5}{|c|}{ Elemental analysis (wt\%) } \\
\hline & $\mathrm{C}$ & $\mathrm{H}$ & $\mathrm{N}$ & S & $\mathrm{O}$ \\
\hline CK1 & 98.1 & 0.3 & 1.0 & 0.5 & 0.1 \\
\hline CK2 & 98.2 & 0.5 & 0.9 & 0.4 & $<0.1$ \\
\hline CK3 & 96.4 & 0.7 & 1.4 & 0.4 & 1.1 \\
\hline
\end{tabular}

\subsection{Characterization of the synthesized materials}

The C, N, S and H content was determined in a LECO- CHNS-932 microanalyzer by burning the sample at $1050{ }^{\circ} \mathrm{C}$. The total oxygen content of the samples was determined directly by pyrolysis at $1350{ }^{\circ} \mathrm{C}$ under helium atmosphere (flow of $225 \mathrm{~mL} / \mathrm{min}$ ) in a LECO-VTF-900 graphite furnace coupled to the microanalyzer.

Coke samples were embedded in an epoxy resin and then ground, using two grades of silicon carbide paper (600 and 1200 grits), and polished successively with two grades of alumina solution ( 0.3 and 0.5 $\mu \mathrm{m})$. Microscopy analysis was conducted using a Zeiss Axioplan microscope. The microscope was equipped with an adjusted eye-piece, onewave retarder plate to record the optical texture of the samples and infinity-corrected oil immersion objective of $20 \times$. Representative photographs of the samples were taken by using a Leica DC100 camera fitted to the microscope. This technique can be used to study anisotropic structures due to its capacity to reflect polarized light in different directions depending on the orientation of the crystallographic domains [22]. Moreover, it can determine the crosslinking grade effect, homogeneity of medium as well as regularity of crystal structure [22].

XRD analysis was performed to derive structural parameters of the synthesized cokes, graphites and thermally reduced graphene oxides. The average graphitic lattice plane distance $\left(\mathrm{d}_{002}\right)$, the lateral size of the crystallite (La), the stacking height of the lattice (Lc) and the average number of aromatic layers $(\mathrm{N})$ were estimated from the spectra [23]. The X-Ray powder diffraction data were collected with a Thermo ARLTM-X'TRA Powder Diffractometer (Thermo Fisher Scientific) with radiation frequency $\mathrm{K} \alpha 1$ from $\mathrm{Cu}(\lambda=1.5406 \AA)$ operating at $40 \mathrm{kV}$ and $45 \mathrm{~mA}$. Measurements of each sample were performed in the scattering $2 \Theta$ range of $5^{\circ}$ to $90^{\circ}$ and $0.01^{\circ}$ step size.

Raman spectra of the different synthesized materials were recorded (without any pre-treatment of the samples), from 750 to $3500 \mathrm{~cm}^{-1}$, on a Renishaw 2000 Confocal Raman Microprobe (Renishaw Instruments, England) using an argon ion laser with a wavelength of $514.5 \mathrm{~nm}$ and power of $2 \mathrm{~mW}$ (Specra-Physics 265).

The images of the synthesized thermally reduced graphene oxides were acquired by means of a FEI NanoSEM 450 FEG scanning electron microscope. In addition, a Thermo Scientific K-Alpha X-ray Photoelectron Spectrometer (XPS) System was used to characterize their surface chemistry. The XPS measurements were carried out using microfocused monochromatic AlK $\alpha$ radiation $(\mathrm{h} \nu=1486.6 \mathrm{eV})$. Surveys were recorded with a pass energy of $150 \mathrm{eV}$ (energy step size: $0.4 \mathrm{eV}$ ) and high resolution regions at $40 \mathrm{eV}$ (energy step size: $0.1 \mathrm{eV}$ ). The $\mathrm{X}$-ray emission angle was $0^{\circ}$ (i.e. $90^{\circ}$ to the surface plane). Wide-scan spectra in the binding energy range of approximately $0-1000 \mathrm{eV}$ were obtained to identify the elements present on the thermally reduced graphene oxide surfaces and to perform a quantitative analysis. To further analyse the surface chemical composition, the $\mathrm{C}(1 \mathrm{~s})$ peak was curve-fitted, emerging six peaks at different binding energies (B.E.), which correspond to $\mathrm{Csp}^{2}$ (B.E. $=284.3-284.4 \mathrm{eV}$ ), $\mathrm{Csp}^{3}$ (B.E. $=285.6-285.7 \mathrm{eV}$ ), COHC-O-C (B.E. $=286.3-286.8 \mathrm{eV}), \mathrm{C}=\mathrm{O}$ in the carbonyl bond (B.E. $=$ 287.6-287.7 eV) and the peak at around 288.5-289.0 eV assigned to the carboxyl bond. The $\pi \rightarrow \pi^{*}$ shake-up signal (B.E. $=290.7-291.3 \mathrm{eV}$ ) typical for $\mathrm{sp}^{2}$ - hybridized carbon was also found.

\section{Results and discussion}

\subsection{Influence of synthesis procedure on the coke characteristics}

CK1 and CK2, both obtained at $900{ }^{\circ} \mathrm{C}$ but from different AO-based pitches (see experimental section), show very similar composition as determined by elemental analysis (Table 1). However, CK3, directly obtained from $\mathrm{AO}$ via microwave heating, presents lower carbon content but higher percentages of hydrogen, nitrogen and oxygen. This might be due to the transition from dipolar heating in molten AO-pitch solution to heating by interfacial polarization in the case of carbon-based solids [24]. This phenomenon coupled with the shortage of the heating time may cause a higher devolatilization.

Despite of these differences in composition, the three cokes exhibit similar optical textures (Fig. 1), suggesting that their structural order could be mainly defined by the characteristics of the initial precursor rather than the thermal approach followed in their synthesis. Cokes appear to be dense with a well-developed and oriented microstructure (needle-like texture). Due to their highly ordered structure, they seem excellent candidates for the production of graphite. Consequently, microwave heating seems a promising approach to obtain suitable graphite and graphene-like precursors.

There is very little difference on the interlayer distance $\left(d_{002}\right)$ of the three cokes, ranging from 0.3514 to $0.3531 \mathrm{~nm}$ (Table 2), despite the different heating process followed during their preparation. The $\mathrm{d}_{002}$ values show that the cokes are still in the pre-graphitization stage, as corresponds to their temperature of synthesis $\left(900^{\circ} \mathrm{C}\right)[25]$. CK3 shows a significantly lower Lc, which is a consequence of its higher content of nitrogen and oxygen compared to CK1 and CK2.

Evaluating the stacking structure using only $\mathrm{d}_{002}$ is difficult. The shape of the 002 carbon peak qualitatively indicates the order degree of the obtained materials [23,26] (Fig. 2). The broad 002 peaks can be ascribed to the small dimensions of the crystallites perpendicular to the aromatic layers [23]. CK1, obtained by conventional thermal treatment, seems to be the most ordered coke, as it presents the lowest $\mathrm{d}_{002}$ and the highest $\mathrm{Lc}(1.51 \mathrm{~nm})$ and $\mathrm{La}(4.75 \mathrm{~nm})$ values (Table 2). However, this is not reflected in its $\mathrm{I}_{\mathrm{D}} / \mathrm{I}_{\mathrm{G}}$ ratio, as CK1 presents the greater value (1.30, Table 2). Consequently, it appears to contradict the widely-reported
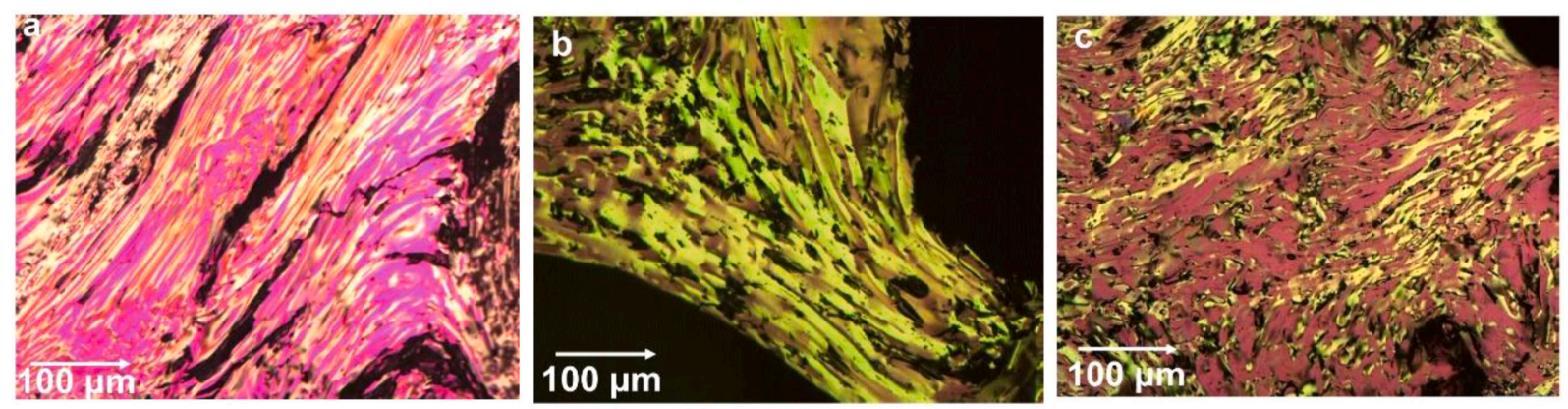

Fig. 1. Optical micrographs of a) CK1 b) CK2 and c) CK3. 
Table 2

Parameters obtained from the X-Ray diffractograms and Raman of the synthesized cokes.

\begin{tabular}{|c|c|c|c|c|c|c|c|c|c|}
\hline & \multicolumn{4}{|l|}{$\mathrm{XRD}$} & \multicolumn{5}{|l|}{ Raman } \\
\hline & $2 \theta$ & $\mathrm{d}_{002}(\mathrm{~nm})$ & Lc (nm) & $\mathrm{n}$ & G position $\left(\mathrm{cm}^{-1}\right)$ & D position $\left(\mathrm{cm}^{-1}\right)$ & FWHM G band $\left(\mathrm{cm}^{-1}\right)$ & FWHM D band $\left(\mathrm{cm}^{-1}\right)$ & $\mathrm{I}_{\mathrm{D}} / \mathrm{I}_{\mathrm{G}}$ \\
\hline CK1 & 25.32 & 0.3514 & 1.51 & 4.3 & 1581 & 1339 & 33 & 70 & 1.30 \\
\hline CK2 & 25.20 & 0.3531 & 1.24 & 3.5 & 1591 & 1344 & 39 & 75 & 1.17 \\
\hline CK3 & 25.21 & 0.3530 & 1.12 & 3.2 & 1592 & 1340 & 44 & 88 & 1.01 \\
\hline
\end{tabular}

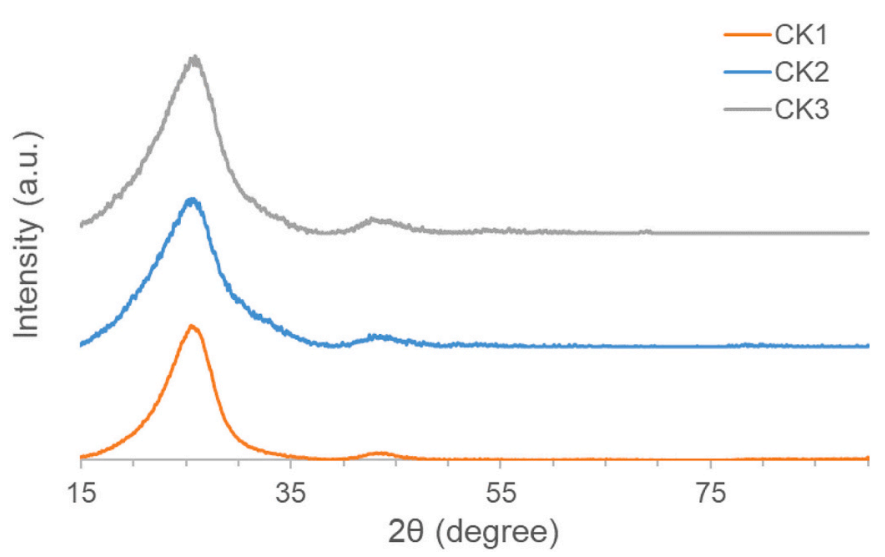

Fig. 2. X-Ray diffractograms of the synthesized cokes.

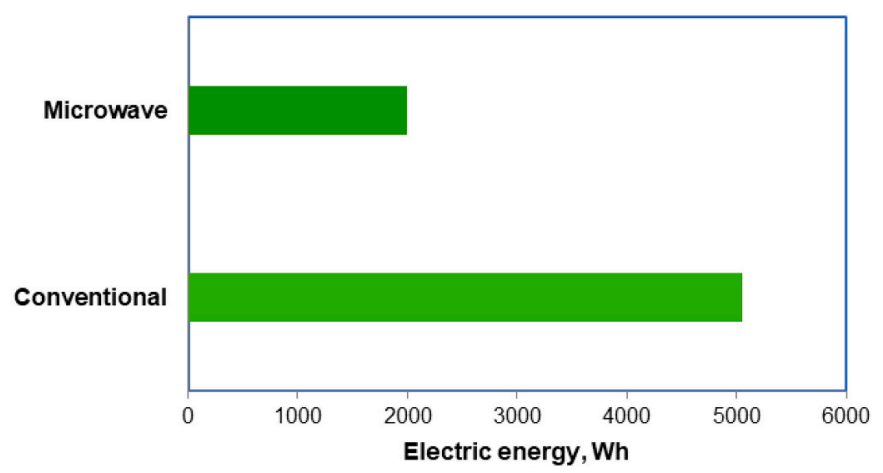

Fig. 3. Assessment of the electricity consumption for microwave and conventional heating.

empirical inverse relationship between $\mathrm{I}_{\mathrm{D}} / \mathrm{I}_{\mathrm{G}}$ and the degree of ordering [27]. Nonetheless, similar results have been found in the literature where it was reported that as the Lc increases, there is a rise in the average number of graphitic planes in the stacking crystalline, $\mathrm{n}$. Therefore edge density is expected to increase as well, giving a higher intensity of the D-band, ascribed to the disorder [28]. This could explain that the $\mathrm{I}_{\mathrm{D}} / \mathrm{I}_{\mathrm{G}}$ ratio can increase with the ordering degree.

In any case, X-Ray analysis and Raman spectroscopy show that parallel layers, composed of condensed aromatic units, occur in the coke structures [29]. However, the size of crystallites as well as the interlayer distance indicate that the three-dimensional stacking of the planes is still limited [25].

However, the reduction in energy consumption reaches up to $60 \%$ for the microwave-assisted coke synthesis compared to the conventional process (Fig. 3). Therefore, the proposed non-conventional heating may represent a viable and energy efficient method for the fabrication of suitable graphene precursors.

\subsection{Characterization of graphites obtained from the different cokes}

Graphites (GR1, GR2, GR3) were obtained from their respective
Table 3

Elemental analysis of the obtained graphites.

\begin{tabular}{|c|c|c|c|c|c|}
\hline & \multicolumn{5}{|c|}{ Elemental analysis (wt\%) } \\
\hline & $\mathrm{C}$ & $\mathrm{H}$ & $\mathrm{N}$ & S & $\mathrm{O}$ \\
\hline GR1 & 99.5 & 0.3 & 0.2 & 0.0 & 0.0 \\
\hline GR2 & 99.7 & 0.1 & 0.1 & 0.0 & 0.0 \\
\hline GR3 & 99.8 & $<0.1$ & 0.2 & 0.0 & 0.0 \\
\hline
\end{tabular}

cokes (CK1, CK2, CK3) with the aim of subsequently producing highadded value graphene-like materials, and therefore to explore the suitability of microwave heating as a more energy efficient method for the synthesis of carbon precursors comparing with traditional procedures [11].

As expected, the produced graphites are mainly carbon, with contents equal or higher than $99.5 \mathrm{wt} \%$ (Table 3). The XRD profiles of the three synthesized graphites are very similar (Fig. 4). As the 002 peak is very intense, the diffractograms in the $2 \theta$ range $40^{\circ}-90^{\circ}$ have been expanded to reveal clearly the existing peaks. The three spectra exhibit the 002, 101 and 004 diffraction peaks present in the typical XRD pattern of natural graphite [30] (Fig. 4). Regardless the production method of the parent coke, the respective graphites show a high degree of crystallinity, as evidenced in the sharp intense peaks and confirmed by the appearance of hkl reflections, especially 10(0),10(1), 11(0), and 11(2) [31].

The 002 peaks are narrow with a maximum at around $26.40^{\circ}$. Additionally, they display the 004 peaks located at $54^{\circ}$ as well as a small reflection at $86.5^{\circ}$, which corresponds to the 006 peak, illustrating a good quality stacking [31]. Furthermore, the hkl reflections at the position of hk bands $(10(0)$ and 10(1)) are well-resolved and the 11 bands located around $78^{\circ}$ are clearly visible (Fig. 3). This band is modulated into $11(0)$ and $11(2)$ reflections (at $\sim 83.6^{\circ}$ ). The presence of the $11(2)$ is classically considered as an evidence of triperiodic order and accordingly of real graphite [31].

Table 4 includes the XRD parameters obtained from the diffractograms, showing the three of them an excellent graphitization degree. The interlayer distances of the synthesized graphites are very similar to the typical graphitic dimensions of $0.3354 \mathrm{~nm}$ [31]. The threedimensional stacking of the planes has occurred in an orderly manner, which allowed the microcrystals' growth with the consequent increase in Lc [30]. GR3 achieves a bit smaller crystallite size and a lower number of aromatic layers ( $\mathrm{Lc}=32.69 \mathrm{~nm}$ and 96.9 layers, Table 4). This can be due to the lesser crystallite dimensions of its parent coke CK3 (Table 2), which has been produced entirely via microwave heating. This is also reflected in the parameters resulting from the Raman spectrum of GR3 (Table 4) where it can be seen its $I_{D} / I_{G}$ ratio is slightly higher than that of GR1 and GR2, suggesting that GR3 presents a greater number of aromatic domains, but smaller in size [32].

In any case, the position and especially the width of the D and G bands of the three samples further reinforce the prevalence of good graphitization. The FWHM of the D bands are much narrower than that of the parent cokes, ranging from 20 to $23 \mathrm{~cm}^{-1}$ (Table 4). The same trend is observed for the $\mathrm{G}$ band, varying from 12 to $14 \mathrm{~cm}^{-1}$, and suggesting better graphitic structure than some highly oriented pyrolytic graphite reported in the literature [31]. 

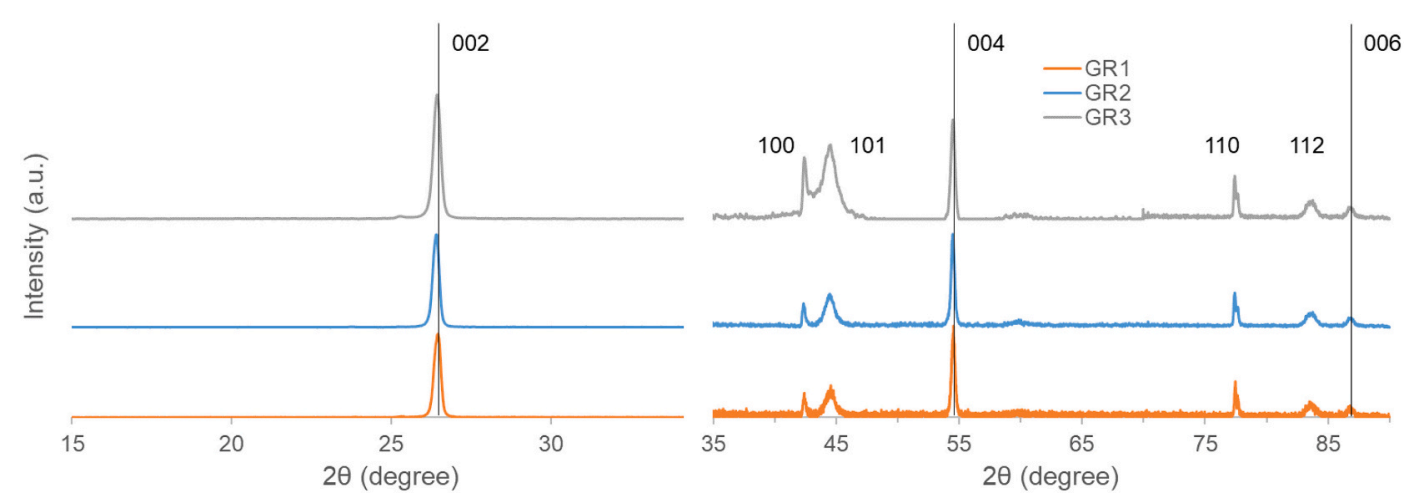

Fig. 4. X-Ray diffractograms of the synthesized graphites.

Table 4

Parameters obtained from the X-Ray diffractograms of the synthesized graphites.

\begin{tabular}{|c|c|c|c|c|c|c|c|c|c|}
\hline & \multicolumn{4}{|l|}{$\mathrm{XRD}$} & \multicolumn{5}{|l|}{ Raman } \\
\hline & $2 \theta$ & $\mathrm{d}_{002}(\mathrm{~nm})$ & Lc (nm) & $\mathrm{n}$ & $\mathrm{G}$ position $\left(\mathrm{cm}^{-1}\right)$ & D position $\left(\mathrm{cm}^{-1}\right)$ & FWHM G band $\left(\mathrm{cm}^{-1}\right)$ & FWHM D band $\left(\mathrm{cm}^{-1}\right)$ & $\mathrm{I}_{\mathrm{D}} / \mathrm{I}_{\mathrm{G}}$ \\
\hline GR1 & 26.41 & 0.3370 & 33.66 & 99.8 & 1563 & 1344 & 12 & 23 & 0.14 \\
\hline GR2 & 26.38 & 0.3376 & 39.46 & 116.7 & 1571 & 1340 & 14 & 20 & 0.15 \\
\hline GR3 & 26.41 & 0.3373 & 32.69 & 96.9 & 1563 & 1337 & 12 & 21 & 0.22 \\
\hline
\end{tabular}
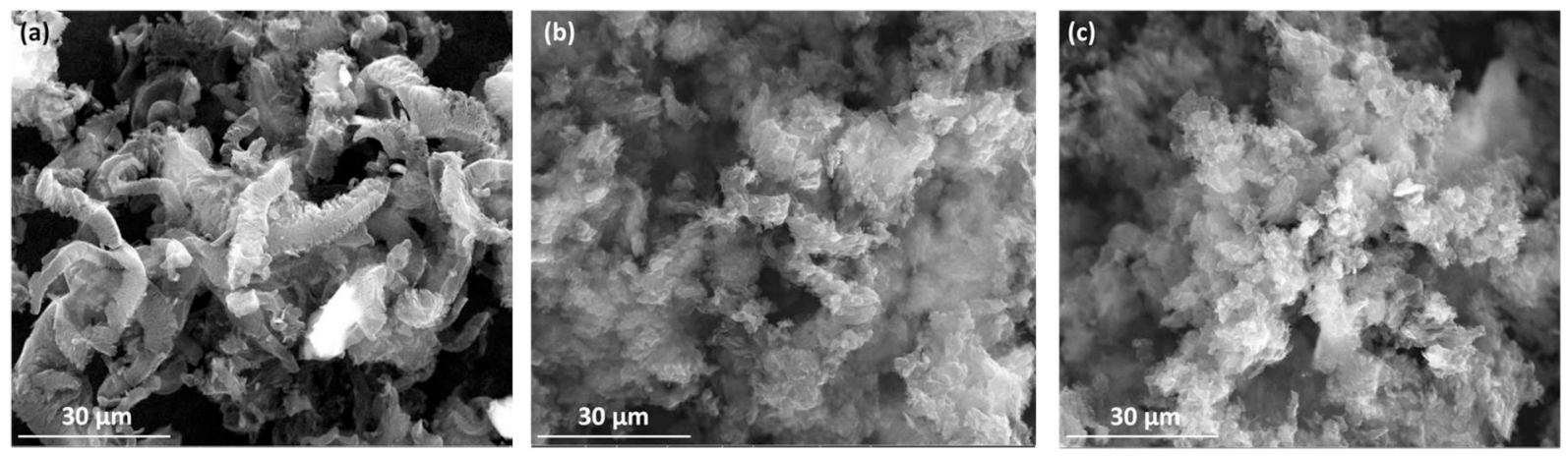

Fig. 5. SEM micrographs of the (a) TRGO1, (b) TRGO2, and (c) (c) TRGO3.

Table 5

Parameters obtained by fitting of the X-Ray diffraction patterns and Raman spectra of the synthesized thermally reduced graphene oxides.

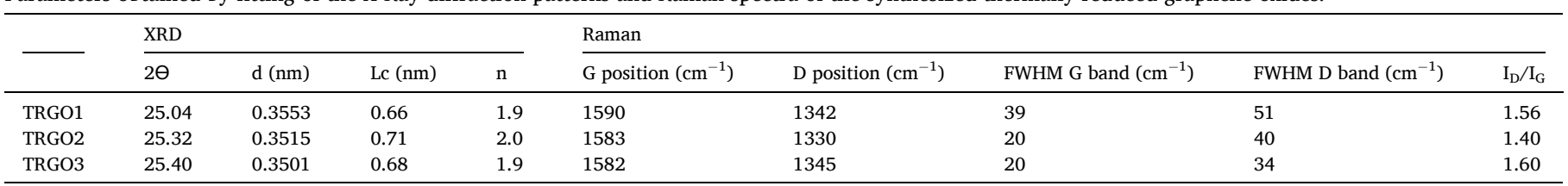

3.3. Characterization of graphene materials from the different precursors synthesized

The chemical route followed for the synthesis of the graphene materials seems to be more effective when microwave-derived starting materials are used. According to the SEM images, graphene materials from microwaved precursors (TRGO2 and TRGO3) appear to be completely exfoliated, while worm-like structures are predominant in the reduced graphene oxides obtained completely via conventional heating (TRGO1) (Fig. 5). This might be due to the slightly smaller $\mathrm{d}_{002}$ distance in GR1, which may hinder the access of the chemicals required for the Hummers method.

All the graphene materials show very similar interlayer distances, being those values slightly lower for TRGO3 obtained from the
Table 6

Elemental analysis of the thermally reduced graphene oxides.

\begin{tabular}{|c|c|c|c|c|c|}
\hline & \multicolumn{5}{|c|}{ Elemental analysis (wt\%) } \\
\hline & $\mathrm{C}$ & $\mathrm{H}$ & $\mathrm{N}$ & $\mathrm{s}$ & $\mathrm{O}$ \\
\hline TRGO1 & 97.6 & 0.3 & 0.3 & 0.5 & 1.8 \\
\hline TRGO2 & 97.6 & 0.6 & 0.4 & 0.4 & 1.0 \\
\hline TRGO3 & 96.7 & 0.4 & 1.1 & 0.4 & 1.4 \\
\hline
\end{tabular}

microwave-derived coke (Table 5). Possible structural alterations and the success of the reduction process have been investigated by means of Raman spectroscopy, as it can manifest itself by the changes in relative intensities of the peaks D and G. The G band appearing between 1576 $\mathrm{cm}^{-1}-1590 \mathrm{~cm}^{-1}$ is the most significant attributes in the Raman spectra of $\mathrm{sp}^{2}$ hybridized materials. The $\mathrm{D}$ peak of the synthesized graphene 
Table 7

Surface composition of the TRGOs and residual oxygen functional groups by curve fitting of C(1 s) spectra.

\begin{tabular}{|c|c|c|c|c|c|c|c|c|c|}
\hline & \multicolumn{9}{|l|}{ XPS } \\
\hline & C (at.\%) & $\mathrm{O}$ (at.\%) & $\mathrm{C} / \mathrm{O}$ & $\operatorname{Csp}^{2}(\%)$ & $\operatorname{Csp}^{3}(\%)$ & C-OH/ C-O-C (\%) & $\mathrm{C}=\mathrm{O}(\%)$ & $\mathrm{C}(\mathrm{O}) \mathrm{OH}(\%)$ & $\pi \rightarrow \pi^{*}(\%)$ \\
\hline B.E. $(\mathrm{eV})$ & & & & $284.3-284.4$ & $285.6-285.7$ & $286.3-286.8$ & $287.6-287.7$ & $288.5-289.0$ & $290.7-291.3$ \\
\hline TRGO1 & 97.3 & 2.7 & 36.0 & 67.7 & 14.2 & 6.4 & 1.5 & 2.8 & 7.4 \\
\hline TRGO2 & 98.1 & 1.9 & 51.6 & 71.5 & 10.3 & 5.8 & 2.3 & 3.5 & 6.6 \\
\hline TRGO3 & 98.4 & 1.6 & 61.5 & 71.1 & 12.5 & 5.5 & 2.7 & 3.4 & 4.8 \\
\hline
\end{tabular}

samples is located between $1330 \mathrm{~cm}^{-1}$ and $1345 \mathrm{~cm}^{-1}$ corresponding to a defect-induced breathing mode of $\mathrm{sp}^{2}$ rings (Table 5 ). The honeycomb hexagonal lattice is recovered to some extent with the reduction process. The bandwidth of the $G$ peak is often used as a measure of the degree of order, being this band narrower for graphene materials synthesized from microwaved precursors. The observed narrowing of D band width in TRGO3 suggests a more uniformed/homogenised carbon structure, resulting from a decrease in both the concentration and distribution of amorphous carbon structures [33].

The bulk oxygen contents are typical for graphene materials reduced at temperatures near $1000{ }^{\circ} \mathrm{C}$ [34] (Table 6). However, it should be emphasised the higher bulk oxygen content of the thermally reduced graphene oxide obtained from the conventionally synthesized precursors (CK1, GR1) in comparison to those derived from microwaved starting materials.

Wide-scan spectra in the binding energy range of approximately 0-1000 eV were obtained to identify the surface chemical composition of the TRGOs. Carbon and oxygen have been mainly detected in the wide scan spectra, as shown in Table 7.

In all the graphene materials most of the carbon atoms are $\mathrm{sp}^{2}$-hybridized, being this amount greater in the samples from microwaved precursors (TRGO2 and TRGO3; > 71\%). Greater amount of oxygenated functional groups has been found on the surface of the graphene-like material obtained conventionally (TRGO1) with an oxygen content of 2.7 at.\%. The C/O ratio determined by XPS (Table 7) suggest a more effective thermal reduction in TRGO3 synthesized from the microwaved coke CK3 (61.5 for TGRO3 vs 36.0 for TRGO1 and 51.6 for TRGO2, Table 7), which is in agreement with the structural differences investigated by means of XRD and Raman spectroscopy and discussed previously (Table 5). These facts further reinforce the potential of the microwave technology as an alternative route for the production of precursors for graphene materials with similar or even improved properties in terms of surface chemistry and structure.

\section{Conclusions}

Cokes synthesized entirely by microwave heating or by a microwaved pitch show similar characteristics than those of a conventional coke produced by thermal treatment, suggesting that their structural order is mainly dependent on the precursor rather than the heating process selected. Moreover, the microwave-assisted technology requires up to $60 \%$ less electrical energy than the conventional heating for their synthesis. Graphites obtained from microwave-based precursors show an excellent degree of graphitization, being the crystallite size smaller in the sample produced from an exclusively microwaved coke. Graphene materials subsequently synthesized using these microwaved precursors show a much significant lattice recovery along with enhanced structure and removal of oxygenated surface functional groups, especially in the case of the thermally reduced graphene oxide from the microwavederived coke. Consequently, microwave technology seems to be a suitable and more energy-efficient approach for the production of excellent precursors of graphite and graphene-like materials.

\section{Declaration of Competing Interest}

The authors declare that they have no known competing financial interests or personal relationships that could have appeared to influence the work reported in this paper.

\section{Acknowledgment}

Authors would like to extend their gratitude to the European Union's Research Fund for Coal and Steel (RFCS) research programme for the received funding under the grant agreement RFCR-CT-2015-00006.

\section{References}

[1] M. Coros, et al., A brief overview on synthesis and applications of graphene and graphene-based nanomaterials, Front. Mater. Sci. 13 (1) (2019) 23-32.

[2] K.S. Novoselov, et al., Electric field effect in atomically thin carbon films, Science 306 (5696) (2004) 666-669.

[3] M.S.A. Bhuyan, et al., Synthesis of graphene, Intern. Nano Lett. 6 (2) (2016) 65-83.

[4] S. Lee, et al., Large-scale production of high-quality reduced graphene oxide, Chem. Eng. J. 233 (2013) 297-304.

[5] A.D. Jara, et al., Purification, application and current market trend of natural graphite: a review, Int. J. Min. Sci. Technol. 29 (5) (2019) 671-689.

[6] A. Oberlin, Carbonization and Graphitization, Carbon 22 (6) (1984) 521-541.

[7] A.L. Fernandez, et al., Carbon precursors from anthracene oil. Insight into the reactions of anthracene oil with sulfur, Energy Fuel 12 (5) (1998) 949-957.

[8] J. Bermejo, et al., Effects of thermal treatment on the composition and properties of air-blown anthracene oils, Fuel 80 (9) (2001) 1229-1238.

[9] L. Fernandez-Garcia, et al., Peculiarities of the production of graphene oxides with controlled properties from industrial coal liquids, Fuel 203 (2017) 253-260.

[10] J. Bermejo, et al., A comparative study of the composition of anthracene oil polymerized by different treatments, Fuel 80 (15) (2001) 2155-2162.

[11] G. Predeanu, et al., Microwave heating as a novel route for obtaining carbon precursors from anthracene oil, Fuel Process. Technol. 192 (2019) 250-257.

[12] J.A. Menendez, et al., Microwave heating processes involving carbon materials, Fuel Process. Technol. 91 (1) (2010) 1-8.

[13] U.O. Mendez, O.V. Kharissova, M. Rodriguez, Synthesis and morphology of nanostructures via microwave heating, Rev. Adv. Mater. Sci. 5 (4) (2003) 398-402.

[14] O.V. Kharissova, Vertically aligned carbon nanotubes fabricated by microwaves, Rev. Adv. Mater. Sci. 7 (1) (2004) 50-54.

[15] F.H. Ko, et al., Purification of multi-walled carbon nanotubes through microwave heating of nitric acid in a closed vessel, Carbon 43 (4) (2005) 727-733.

[16] Y.B. Wang, Z. Iqbal, S. Mitra, Microwave-induced rapid chemical functionalization of single-walled carbon nanotubes, Carbon 43 (5) (2005) 1015-1020.

[17] L.T. Drzal, H. Fukushima, B. Rook, M. Rich, Continuous Process for Producing Exfoliated Nano-Graphite Platelets, 2006. US - Application number 20060241237.

[18] W.S. Hummers, R.E. Offeman, Preparation of graphitic oxide, J. Am. Chem. Soc. 80 (6) (1958) 1339.

[19] P. Alvarez, et al., Preparation of low toxicity pitches by thermal oxidative condensation of anthracene oil, Environ. Sci. Technol. 43 (21) (2009) 8126-8132.

[20] A.L. Fernandez, et al., Air-blowing of anthracene oil for carbon precursors, Carbon 38 (9) (2000) 1315-1322.

[21] P. Alvarez, et al., Tuning graphene properties by a multi-step thermal reduction process, Carbon 90 (2015) 160-163.

[22] I. Suarez-Ruiz, J.C. Crelling, Applied Coal Petrology: The Role of Petrology in Coal Utilization, Academic Press, 2008.

[23] H. Takagi, et al., XRD analysis of carbon stacking structure in coal during heat treatment, Fuel 83 (17-18) (2004) 2427-2433.

[24] T. Kim, J. Lee, K.H. Lee, Microwave heating of carbon-based solid materials, Carbon Lett. 15 (1) (2014) 15-24.

[25] D.B. Fischbach, Chemistry and Physics of Carbon vol. 7, Marcel Dekker, New York, 1971.

[26] S. Gupta, et al., Carbon structure of coke at high temperatures and its influence on coke fines in blast furnace dust, Metall. Mater. Trans. B-Process Metall. Mater. Proces. Sci. 36 (3) (2005) 385-394.

[27] F. Tuinstra, J.L. Koenig, Raman Spectrum of Graphite, J. Chem. Phys. 53 (3) (1970) 1126.

[28] D. Shanning, Development of Analytical Methods for Characterizing Metallurgical Coke and the Injectant Coal Chars, Tars and Soots Formed During Blast Furnace Operation in Department of Chemical Engineering, Imperial College London, 2008.

[29] S. Jasienko, B. Bujnowska, Properties and Structure of Metallurgical formed Cokes, Fuel Process. Technol. 6 (2) (1982) 123-135. 
[30] A.I. Cuesta Seijo, Factores determinantes de la reactividad de fibras de carbono y otros materiales carbonosos, in: Departamento de Química Física y Analítica, University of Oviedo, 1994.

[31] M.B. Vazquez-Santos, et al., Comparative XRD, Raman, and TEM study on graphitization of PBO-derived carbon fibers, J. Phys. Chem. C 116 (1) (2012) $257-268$.
[32] S. Vizireanu, et al., Carbon nanowalls growth by radiofrequency plasma-beamenhanced chemical vapor deposition, Plasma Process. Polym. 5 (3) (2008) 263-268.

[33] L. Abello, et al., Fine-structure investigations of diamond and diamond-like carbonfilms using Raman-spectroscopy, Diam. Relat. Mater. 1 (5-6) (1992) 512-518.

[34] C. Botas, et al., Critical temperatures in the synthesis of graphene-like materials by thermal exfoliation-reduction of graphite oxide, Carbon 52 (2013) 476-485. 